\title{
"Adding Stuff From Other People": How Peer Comparison Influences Conceptual Modeling in Precollege Engineering Contexts
}

\section{Ms. Katelyn Stenger, University of Virginia}

Katelyn Stenger is a Ph.D. fellow in the Behavioral Science for Sustainable Systems program at the Convergent Behavioral Science Initiative at the University of Virginia. She researches behavioral designs for complex systems. Previously, she worked as a mechanical engineer helping design and construct high-rise buildings. She received her B.S. in Mechanical Engineering from Rose-Hulman Institute of Technology.

\section{Prof. Jennifer L. Chiu, University of Virginia}

Jennifer Chiu is an Associate Professor of STEM Education at the University of Virginia School of Education and Human Development. She holds a B.S. in Engineering (Product Design) from Stanford University and an M.A. and Ph.D. in Science Education from UC Berkeley. She researches how to support K-12 students, teachers, and preservice teachers across science, engineering, mathematics, and computer science disciplines as well as how to support STEM in informal learning contexts. Before becoming a professor, she worked as an engineer at Hewlett Packard and taught high school mathematics and science in California and Oklahoma.

\section{Dr. Sarah Jennings Fick, Washington State University}

Sarah J Fick, Ph.D. is an assistant professor of Science Education in the Department of Teaching and Learning at the College of Education at Washington State University. She holds a BA in Biology and Environmental Studies from Bowdoin College, an MA in Science Education, an MS in Environmental Informatics, and a PhD in Science Education, all from the University of Michigan. Her research focuses on using qualitative methods to understand the intersection of teaching and learning in science education. She specifically focuses on the teaching practices needed to support students' to develop knowledge of the content, practices, and analytical lenses used to develop science knowledge. 


\title{
"Adding stuff from other people's": how peer comparison influences conceptual modeling in precollege engineering curriculum
}

\begin{abstract}
Conceptual models serve as both as a design artifact and an object that communicates understanding about underlying systems. As such, conceptual modeling is considered as a crucial component of engineering design. Peer comparison and critique can help students develop conceptual models, yet little research explores how peer comparison activities can support conceptual model development in engineering settings. Therefore, we investigate why and how fifth-grade students made changes to their conceptual models after a peer comparison during a 4week engineering design curriculum unit focused on water runoff at their school. Data sources included students' conceptual models before and after the peer comparison, field notes, and student interviews after the peer comparison. To understand how students described their conceptual models and why any changes may have occurred, we interviewed twelve students and coded these interview transcripts at the utterance level. Results show that peer comparison activities can increase conceptual model quality. Further, peer comparison contributes to a diverse set of additional representations in students' conceptual models. The study suggests peer comparisons of conceptual modeling may support students in realizing their peers are a great source of information, a critical realization to support positive engineering design experiences in K-12 and higher education.
\end{abstract}

\subsection{Introduction}

Conceptual modeling has been described as the most important step in engineering design [1], [2]. Developing and using conceptual models involves creating representations of how a system works, which help people know, understand, or simulate a subject the model represents [3]-[6]. These representations include underlying structures, relationships, and processes which aid in understanding underlying systems of the engineering design problem [3], [4], [7]. Research on professional engineering design practices indicates the importance of conceptual modeling as an interoperable representation to generate and synthesize understanding between various audiences [8]; thus acting as a critical tool in engineering design practice [9].

In engineering education, conceptual models have been identified as a crucial artifact to support student learning and facilitate communication between students and teachers [10]. Students can use conceptual models as a design artifact to support engagement in engineering design. By considering learning as a socio-material process, student-generated conceptual models serve as a material representation that can support learning from peers. Such activities include comparing and contrasting conceptual models with other students, referred to as a peer comparison or critique activities. Students can communicate information from conceptual models in a different way when communicating with peers rather than with teachers and instructors, resulting in potentially different forms of engagement and learning [11]. 
The goal of this paper is to understand how peer comparison can influence the quality of conceptual models within an engineering design task in elementary classroom contexts. We investigate the effects of structured peer comparison to help students develop conceptual models. We explore the changes in quality of conceptual models and students' thoughts about the peer comparison activities in a post-activity interview. By exploring how elementary students develop conceptual models during a 4-week engineering design curriculum unit, we aim to inform the field as to how to support conceptual modeling in precollege engineering contexts.

\subsection{Background}

\subsection{Conceptual modeling within engineering design education}

One of the most pervasive features of science, engineering, and technology is the use of visual representation in the form of conceptual models, diagrams, tables, equations, and drawings [12]. Further, engineering can be thought of as a discipline that teaches students to transform one set of representations into another: text to diagram to symbol [13]. Visual representations are important not only to communication, but also to teaching and learning.

Such visual representations include conceptual models, which both communicate and facilitate communication between audiences of different expertise (e.g., peers, instructors, stakeholders) in engineering and engineering education [14]-[16], and provide a unique way to shape knowledge construction for engineering in K-12 education. Prior research has explored how to help students develop and apply conceptual models in engineering contexts at undergraduate levels [17], [18], and precollege science contexts [19], [20]. A conceptual model is a representation of a system to help people know, understand, or simulate a subject the model represents and often is composed of concepts in visual symbols, signs, and words [10]. As such, activities that elicit conceptual models can support learning in classrooms [7], [21]-[23]. For instance, a study found that conceptual models supported fifth-grade students to apply core science and engineering concepts to an engineering design task [22].

\subsection{Peer Comparison as Facilitating Social Learning}

In this work we see learning as socially situated. It is through interactions with others and tools that individuals change their understanding [24], [25]. Engineering education is a tool-based discipline, with tools such as conceptual models and prototypes supporting learning, understanding, and collaborating at all stages of design [9]. Representations like conceptual models get their meanings from their use [26]. These conceptual models, which serve as tools for learning, require a learner to engage with it in context for it to have meaning. For example, a student who compared, and discussed their conceptual model with another student would be highly engaged, and likely better suited to learn.

Where conceptual models provide a material design artifact, peer comparison facilitates social engagement. In short, a conceptual model is a visual stimulus that is a starting point for discussing ideas and knowledge between students. Knowledge arises conceptually through dynamic construction and/or reinterpretation within a specific social context [27]. Furthermore, knowledge is socially reproduced and learning occurs through participation in meaningful 
activities that are part of a community of practice [28]. Peer comparison activities allow for a conversation about each student's conceptual model and knowledge. Even more, communicating effectively to peer audiences is an important practice of engineering, and much needed for the learning of engineering practices in educational settings. Therefore, by incorporating peer comparison and conceptual modeling, we are maximizing opportunities for student learning about engineering design.

Engineering design, and design more broadly, has been described as a conversation [29], [30]. Artifacts of design enact a conversation with students and serve as a shared reference point for understanding. Artifacts like conceptual models help to visually communicate and support active learning among students [31] and can be amplified by peer comparison activities.

While peer comparison is used widely in engineering design education, limited research exists that investigates peer comparison on the act of conceptual modeling and conceptual model quality. Peer comparison is an activity in which pairs of student peers compare and communicate their individual approaches to a task. Peer comparison can be useful for engineering design contexts where students approach the task in diverse ways. Peer comparison can accustom students to the real-world practice of sharing understanding of the engineering design context [32]. Even more, peer comparison activities support student in realizing their peers are a source of knowledge and support [33], [34].

A key characteristic of peer comparison is verbal feedback between the students. In prior studies, verbal feedback can elicit more elaboration on critiques of peer work, when compared to written feedback [35]. Even more, such verbal feedback can be more constructive for students in a design curriculum [36]. As such, verbal feedback plays a significant role in success and team performance for students in engineering design curriculums [37]. Prior research shows evidence that elementary students have navigated the demands of giving engineering design peer feedback [38]. Even more, student discourse helps students to understand how their drawn designs (e.g. conceptual models) can be used during an engineering design challenge in an elementary science classroom [39].

Peer comparison can also facilitate student reflection. Through reflection, students can evaluate the pros and cons of student models, intentionally select solutions, and purposefully choose improvements. Prior studies demonstrate that reflection can help elementary students redesign their conceptual models during engineering design [40]. In this way, reflection plays an important role in helping elementary students develop conceptual models as part of engineering design.

Thus, this study investigates the role of peer comparison on the development of elementary students' conceptual models. This study explores how and why students change conceptual models of a water system after drawing conceptual models, engaging in a peer comparison activity, and reflecting on their experiences. 


\subsection{Methods}

\section{$\underline{\text { 3.1 Participants }}$}

The study took place with two fifth-grade classrooms in an upper elementary school in the southeastern United States. Fifth grade students $(\mathrm{n}=44)$ across two classes participated in the study. District student demographics include 31\% Black, 13\% Hispanic/Latinx, 6\% Asian/Pacific Islander, $41.7 \%$ White, and $9 \%$ of $2+$ or Other races, with $14 \%$ of students speaking 51 different languages. Additionally, $44 \%$ of students qualify for free or reduced-price lunch. Student demographics in the classes were similar to district demographics. Two teachers co-taught both fifth-grade classrooms.

\subsection{The Activity}

In this paper, students were provided with structured opportunities to make observations and discuss what each person chose to include in their model. It was expected that through these comparisons and discussions students' might consider ways that other models included information might be incorporated into their own. Through these socially-based learning opportunities students had the opportunity to compare and discuss the different things that were represented [24].

The conceptual modeling activity was part of a 4-week engineering design curriculum unit that integrated engineering, science and computational modeling focused on water systems [41]. The engineering design problem centered on reducing flooding of the school's recess field. The context was specifically designed to leverage students' own experiences with the school's water system as resources to use during the modeling activities. Students engaged in conceptual modeling of where water goes during rainfall to inform the development of a computational model and their design solutions [42]. This study focuses on a lesson within the unit where students generate an initial model of runoff at their school, compare their models to three other students' models in a structured activity, and subsequent revision of their own conceptual model, shown in Figure 1. 

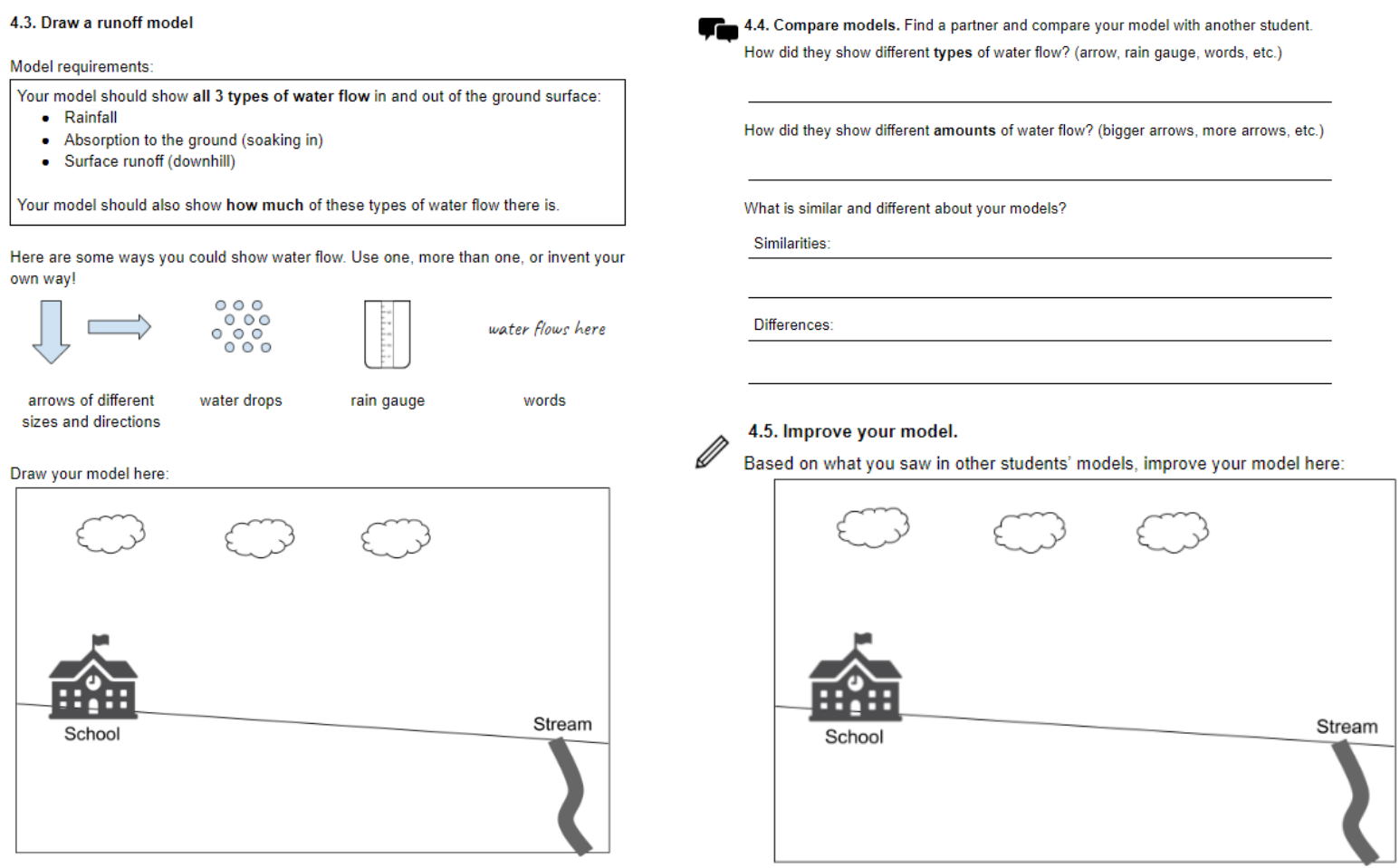

Figure 1. Photos of curriculum section

Five days into the 4-week engineering design curriculum, students drew a conceptual model of the engineering design context (i.e., flooding of their school) pulling from knowledge developed in prior lessons, shown in Figure 1. After drawing their conceptual models, students were paired with another student to share and discuss their conceptual models from Lesson 4.3 (the conceptual model before peer comparison). Students discussed in pairs for two minutes. After this time, one student would move seats to form a new student pair for two more round, for a total of three sessions of peer comparison on the first model. During this time, students could write observations from the prompts provided in 4.2. After the peer comparison, students were given two minutes to reflect on their observations and discussions with their peers and revise their model in 4.3 (the conceptual model after peer comparison).

\subsection{Data collection}

Data sources included students' conceptual models, student interviews, and field observations. Students' conceptual models included students' initial and revised artifacts in their physical student workbooks. Of the 44 students in the class, we used data from 39 students who had complete initial and revised models. Student interviews were conducted with 12 of the 39 students who had complete pairs, 6 from each class. We selected 12 students who had signed consent forms and interviewed a quarter of the population to gather understanding of the tasks. The timeline of data collection relative to Peer Comparison of Conceptual Models is shown in Figure 2 below. 


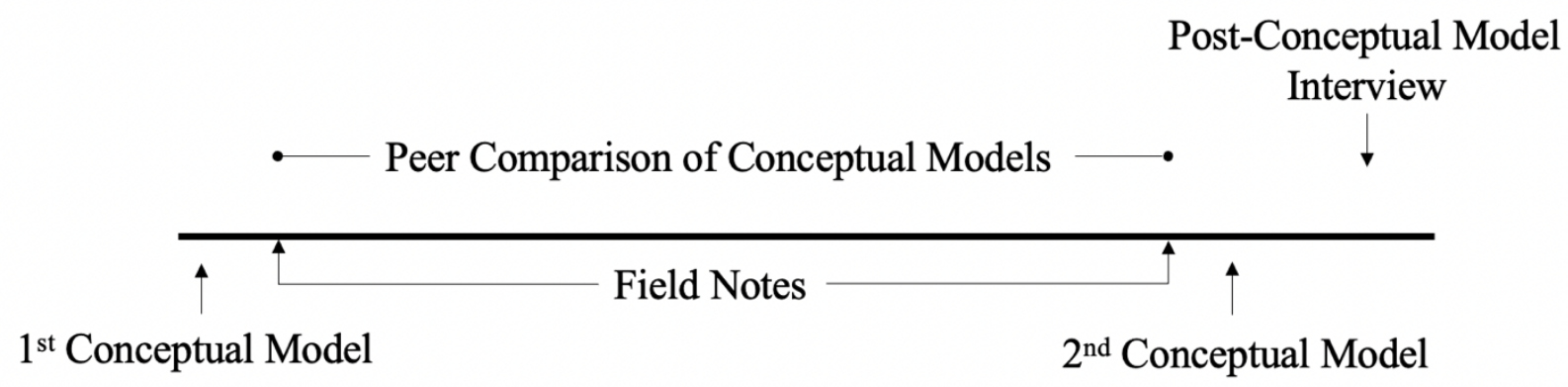

Figure 2: Timeline of data collection relative to Peer Comparison of Conceptual Models

The conceptual models were collected after the 4-week curriculum unit. Semi-structured interviews were conducted with the students after the second conceptual model, lasting between four to nine minutes with the following questions.

1) For the first model (Fig. 1: 4.3 Draw a runoff model), what did you draw? Why?

2) For the second model (Fig. 1: 4.5 Improve your model), what did you draw? Why? Is there more or less of anything? Why?

3) You compared models with other students in the activity. Whose model did you look at? Did you talk to each other? If so, what did you talk about? What did you notice about their model? Did that influence how you improved your model?

Interviews were used to understand how and why students revised their models and what students were intending to communicate in their conceptual models. Interviews also helped to clarify the researcher's bias in interpreting the conceptual models and allowed for member checking on how to interpret representations. Field notes were taken by the first author and provided context for the classroom activities.

\section{$\underline{\text { 3.4 Data Analysis }}$}

Students' conceptual models were coded to capture understanding of the targeted water systems. We measured quality in two dimensions for conceptual models: pictorial and numerical. Pictorial quality was the accuracy of the conceptual model in representing conservation of mass by using sketches and other semiotics (e.g., arrows). Numerical quality was the accuracy of the conceptual model in representing conservation of mass by using numerical representations (e.g., numbers).

To understand how students described their conceptual models and why any changes may have occurred in the student interviews, we coded interview transcripts at the utterance level, where each sentence was one utterance.

The first and second authors coded $20 \%$ of conceptual models (Table 1) and reached an interrater agreement of 0.96 . We used Lincoln and Guba's framework [43]; seeking to build credibility by triangulations between conceptual models, interviews, and field notes and transferability by showing our observations, interviews, and process for analysis [43]. We overlapped our methods, conceptual modeling coding, interviews, and field observations to build dependability and facilitate credibility. Lastly, we wanted to enhance the authenticity of our 
research and share the local meaning defined by participants of sharing conceptual models with other students, and what they were representing in the conceptual model through interviews.

\section{Table 1 - Quality Coding Book}

\section{Numerical Response}

\begin{tabular}{l|l|l}
\hline Short Description & Description & Code \\
\hline Correct & Amount of Rain = Amount of Runoff + Amount of Absorption & 3 \\
\hline $\begin{array}{l}\text { Incorrect amount of Rain, } \\
\text { Absorption and/or Runoff }\end{array}$ & Amount of Rain =/= Amount of Runoff + Amount of Absorption & 2 \\
\hline No Amount of Rainfall & $\begin{array}{l}\text { Amount of Rain = 0 while } \\
\text { Amount of Runoff + Amount of Absorption }>0\end{array}$ & 1 \\
\hline Blank & No Numerical Response & 0 \\
\hline
\end{tabular}

Pictorial Response

\begin{tabular}{l|l|l}
\hline Short Description & Description & Code \\
\hline $\begin{array}{l}\text { All Parts with an } \\
\text { absorption limit }\end{array}$ & $\begin{array}{l}\text { Shows or uses text to describe water being absorbed into the ground until } \\
\text { it hits a limit resulting in runoff, or not exceeding the limit (limit can be a } \\
\text { full/partially fully/overflowing cup) }\end{array}$ & 4 \\
\hline All Parts & $\begin{array}{l}\text { Shows all required elements of the correct model - rainfall AND } \\
\text { absorption and/or runoff OR a complete equation }\end{array}$ & 3 \\
\hline Some Parts & $\begin{array}{l}\text { Shows only some of the required elements of the correct model - } \\
\text { absorption and/or runoff OR a partial equation in the box }\end{array}$ & 2 \\
\hline Rainfall & Shows only rainfall & 1 \\
\hline Blank & No Pictorial Response & 0 \\
\hline
\end{tabular}

Once the quality of the conceptual models was recorded, we calculated a difference of quality by subtracting the model quality before the activity from the model quality after the activity for both pictorial and numerical quality scores. To synthesize this data, we characterized conceptual models into five categories: no change in pictorial or numerical quality, positive change in pictorial quality, positive change in numerical quality, negative change in numerical quality, and negative change in pictorial quality. Conceptual models could fall into multiple categories (e.g., positive change for numerical quality but negative change for numerical quality). 
We characterized themes for changes in quality of the students' conceptual model by triangulating between interview data, field notes, conceptual model artifacts, and conceptual model quality and numerical scores. We first grouped students by their changes. We paired the conceptual models, the respective numerical and pictorial scores, and relevant interview excerpts within a document. We also compared non-interviewed student models to these interviews. After two iterations of comparison and notes, we identified emergent themes between scores and the peer comparison for each category of scores. Below we provide synthesis of student conceptual models, subsequent scores, and interview data.

\subsection{Findings}

\section{$\underline{4.1 \text { Quality of Conceptual Models }}$}

Students both increased and decreased in model quality after the peer comparison activity. The changes in model quality are shown in Figure 3 and quantified in Table 2. Students who were interviewed are indicated by a red point, and students who were not interviewed are indicated by a black point; Figure 3 has points jittered by $+/-.2$ to help show clusters.

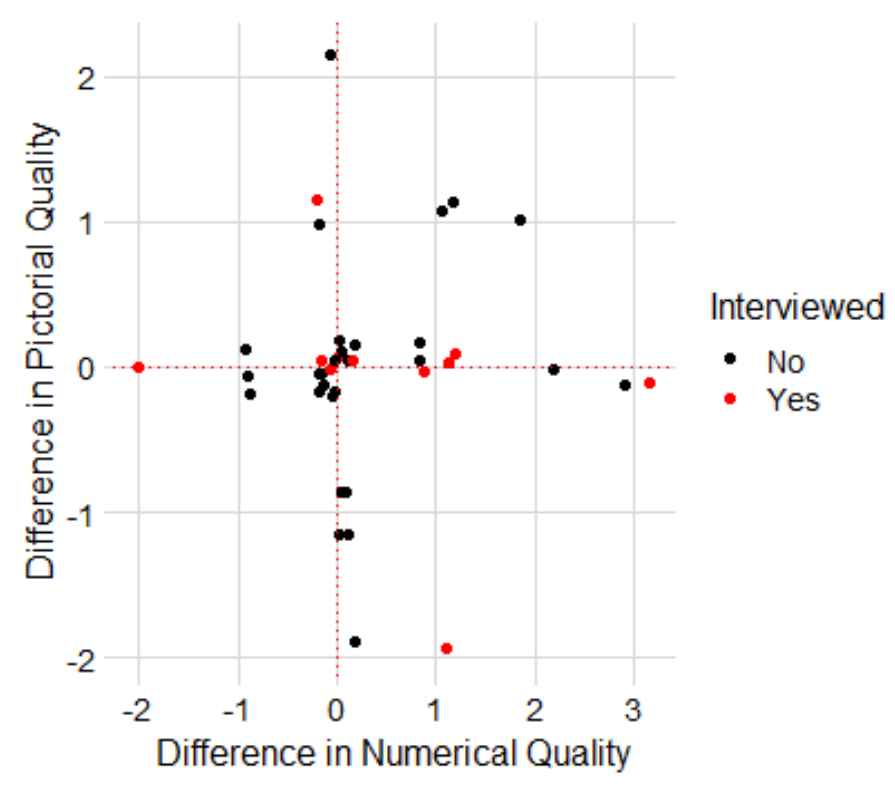

Figure 3: Differences in Quality for Numerical and Pictorial Quality

Table 2 - Changes in Pictorial and Numerical Quality of Conceptual Models

\begin{tabular}{|c|c|c|c|c|c|c|}
\hline & -2 & -1 & $\mathbf{0}$ & 1 & 2 & 3 \\
\hline Pictorial & $2 / 39$ & 4 & 27 & 5 & 1 & 0 \\
\hline Numerical & $1 / 39$ & 3 & 23 & 8 & 2 & 2 \\
\hline
\end{tabular}


In Figure 3, the changes in numerical model quality are shown on the horizontal axis valued from -2 to +3 , and the changes in pictorial quality are shown on the vertical axis valued from -2 to +2 . Most conceptual models did not change in quality from the activity, with 27 out of 39 showing no change for pictorial model quality and 23 out of 39 for numerical model quality. Three students increased in both numerical and pictorial quality. No students decreased in both numerical and pictorial quality. Four students decreased in numerical quality but showed no change in pictorial quality. Five students decreased in pictorial quality but showed no change in numerical quality.

We recognize that four students' conceptual models changed in both dimensions. For this reason, we will analyze them as contributors to both cases, to conservatively characterize model changes. In the following sections, we synthesize sources of evidence for each case. For each student interviewed, we provide the conceptual models before and after the activity, their numerical and pictorial quality scores, and interview excerpts about any changes the students may or may not have done. We briefly summarize observations and interpretations throughout the interview.

\subsubsection{No change in pictorial or numerical quality}

Noticing descriptive details unrelated to process or numbers: All students interviewed shared that they noticed details of their conceptual models during the activity. For instance, Student 6 noticed missing representations in their conceptual model. Students 5 and 12 expressed they added additional descriptive details to their models like parking lots, arrows, words, and sediment to their second models. While noticing details and context is important to any engineering design activity, the way in which quality was determined showed that many students (27/39 students for pictorial quality and 23/39 students for numerical quality) did not change in quality. Below we provide the conceptual models of Student 5, shown in Figure 4.

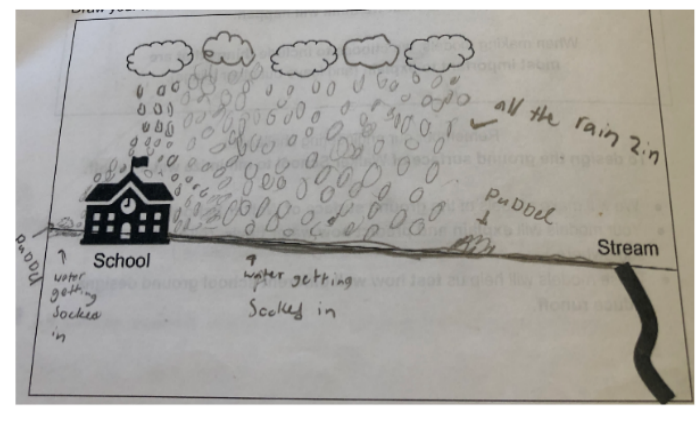

(a) Before activity

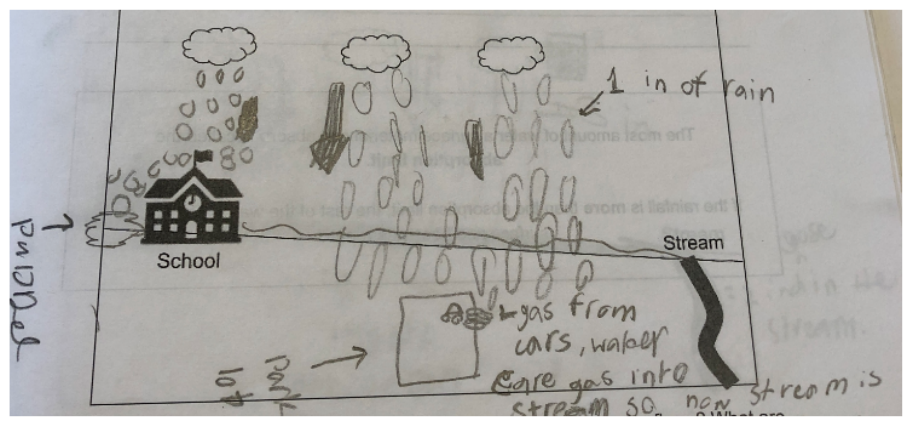

(b) After activity

Figure 4: Conceptual models of Student 5

Student 5's conceptual model before the peer comparison scored a 1 for numerical quality and a 3 for pictorial quality. After the peer comparison activity, their conceptual model scored a 1 for numerical quality and a 3 for pictorial quality (Figure 4). Student 5 noted how they added ideas from the peer comparison activity: 
Student 5: Kind of the same thing, but I got an idea from my friend, M, she drew the parking lot and there's gas from the cars and the water washed away and the gas from the cars put it into the stream too to make it more kind of polluted.

Student 5 shared that many students had similar conceptual models, except for one of their friends.

Student 5: Most of the people that I had looked at their model is really similar to mine, but my friend was the only one who had a different one. And I didn't meet with her but we had extra time so she was telling me about how like gas from the cars could pollute the stream, and I thought that that was a good idea cause that was happening.

Interviewer: Yeah, um, so, so your new ideas did not come from the like speed dating model comparison. It came from you sitting down with your friend and talking about your ideas.

Student 5: Yeah.

Even more, Student 5 shared that the conceptual model provided enough information to understand other students' mental models:

Student 5: Um, most of them use arrows instead of drawing a lot of the rain and they do like big arrows and small arrows and they didn't really describe what was happening, it was just a picture and you kinda had to figure it out.

Lastly, Student 5 expressed that other people influenced their conceptual model:

Interviewer: So, did that talking to other people influence your model at all?

Student 5: It did, cause the first person I talked about how using arrows and how the bigger one means more rain and the smaller means less rain, and so I used that in my improved drawing.

\subsubsection{Positive change in numerical quality}

Noticing numbers and rain gauges increased numerical quality: Increases in numerical quality often begin with a student noticing a rain gauge or numbers on another student's conceptual model, as evident in both Student 3, Student 7, and Student 8 interview data. Interestingly, Student 12 listened to instructor when they indicated to write the amount of water. 


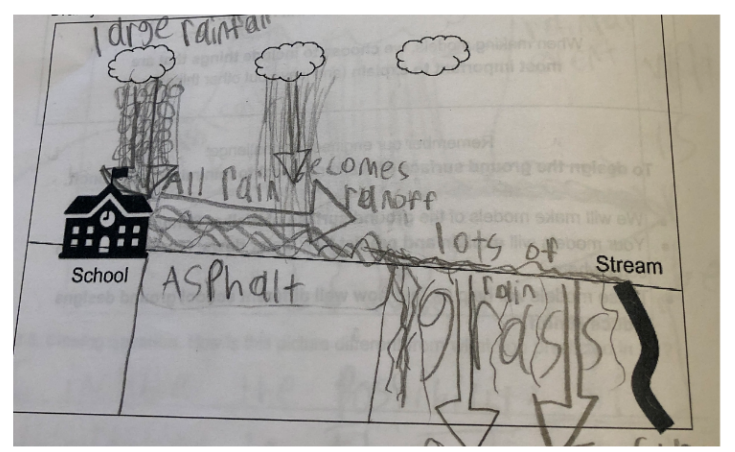

(a) Before activity

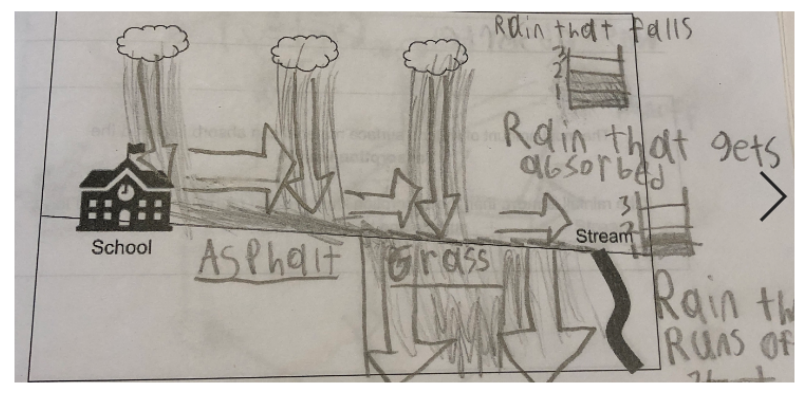

(b) After activity

Figure 5: Conceptual models of Student 7

Student 7 scored a 0 in numerical quality and a 4 in pictorial quality for the conceptual model before the activity and scored a 3 in numerical quality and a 4 in pictorial quality for the conceptual model after the activity (Figure 5). Student 7 shared they noticed rain gauges from another student during the activity, a representation to show the numerical quantity of rain. Student 7 also expressed they added rain gauges to the second model, which increased their numerical quality score:

Interviewer: Okay. So, let's talk a little bit about the social comparison of the models. When you talk with other people whose model, did you look at?

Student 7: Uh, T's model, he, that was the one that influenced me to make it, to make rain, to add rain gauges.

Interviewer: Did you, um, talk to each other about your models?

Student 7: Yeah, I think I, I think he was interested by why I by at how I divided it up into sections, he just assumed that all the of it was grass, so, so I think he, I think he, uh, added that to his second model

Interviewer: Was there anything else that you've talked about the T's model?

Student 7: About how he used rain gauges and how those helped the observer understand the model, that's why I added those.

\subsubsection{Positive change in pictorial quality}

Representing previously absent processes increased pictorial quality: Increases in pictorial quality were attributed to adding additional detail to the conceptual model as it related to communicate previously absent process (rainfall, absorption, and runoff), or an absorption limit as Student 9 has demonstrated in their conceptual model after the activity (Figure 6). While Student 9 did not indicate why they added the limit in interview, it is plausible they observed a limit from another student not interviewed. 


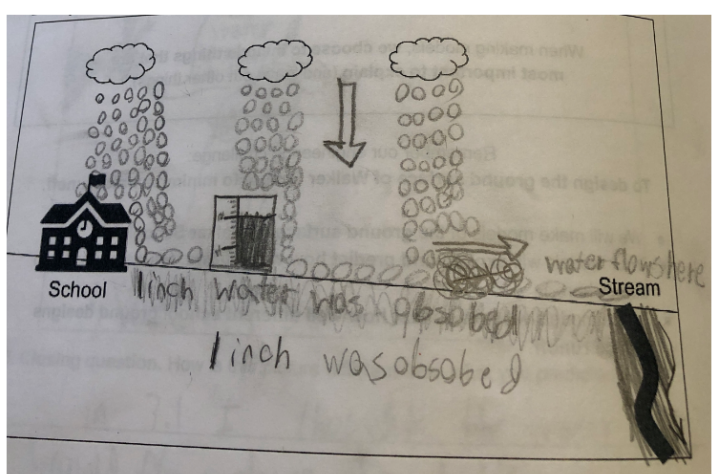

(a) Before activity

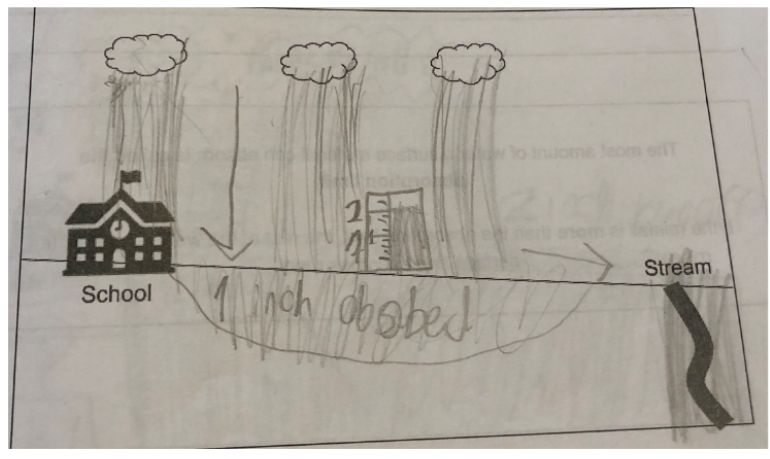

(b) After activity

Figure 6: Conceptual models for Student 9

Student 9 scored a 2 in numerical quality and a 3 in pictorial quality for the conceptual model before the activity and scored a 2 in numerical quality and a 4 in pictorial quality for the conceptual model after the activity (Figure 6). Student 9 shared that they added a perimeter, interpreted as an absorption limit, in their second model that increased the pictorial quality of the second model:

Student 9: So, I notice that over here there was too much water drops, so then, um, and it was too much time. So, then I drew lines and then I kind of like made a perimeter around here to show that it was raining there because it kind of does not make sense. They like over here, but the clouds are like over here.

Even more, Student 9 shares that they believe their model influenced how another student represented their second model by adding a rain gauge:

Student 9: Um, we talked about uh, how they look alike, how they don't, we talked about um, um, the measurements of water, he did not add a rain gauge, and I think after he did.

\subsubsection{Negative change in numerical quality}

From our data sources and analysis, it was unclear what contributed to decreased numerical quality. It is plausible that students who scored a lower numerical score after the peer comparison forgot to transfer numerical representations, deemed it unimportant to the model, or did not have enough time to detail their second model, as Student 8 indicated. 


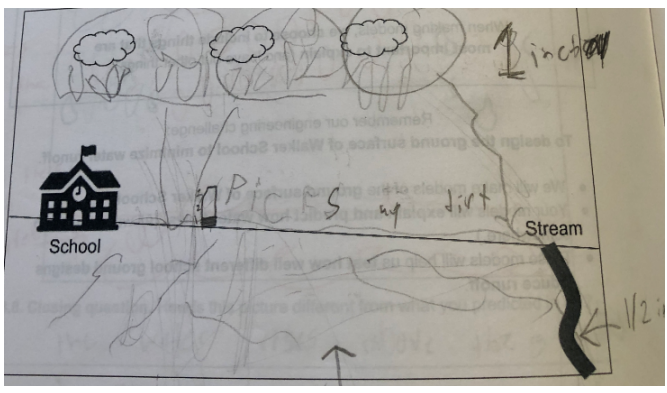

(a) Before activity

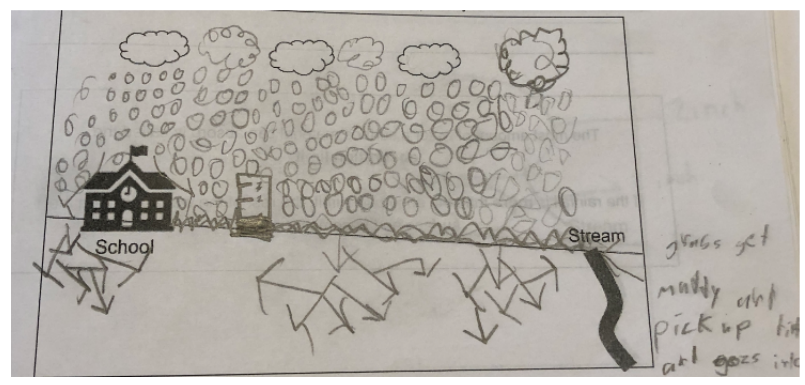

(b) After activity

Figure 7: Conceptual Models from Student 2

Student 2 conceptual model quality before the peer comparison scored a 3 for Pictorial and a 4 for Numerical quality. After the peer comparison, Student 2 scored a 3 for Pictorial and a 1 for Numerical quality (Figure 7). Student 2 expressed that the peer comparison activity aided in understanding other students' conceptual models, and understanding their ideas:

Interviewer: How did that process [talking with other students] go?

Student 2: It helped a lot. Cause I can see other people's ideas. So, I noticed that people had smaller raindrops but a lot."

Student 2 also expressed how the peer comparison fit and the conceptual modeling exercise related to defining the problem, and how such activity informed the remaining engineering design project:

Student 2: Okay. So, we have to define the problem and investigate, create test, and then find, and you could like create design, test it, and if it doesn't work you have to investigate back to here. I'm excited for the great design, we'll still need to do.

Student 2 clearly expressed that the activity helped understand other student's ideas, and how the activity fit into the larger engineering design curricular unit. Yet, Student 2 did not write numerical quantities runoff or absorption and decreased in numerical quality. It is uncertain why Student 2 did not represent the numbers in the second model.

\subsubsection{Negative change in pictorial quality}

Uneven time durations in peer comparison activity: Student 8 expressed they had a long amount of time with one student, and not enough time with other students during the activity. In addition, Student 8 might be suggesting that the time spent to draw the second model was substantially shorter than the first session. These findings suggest the importance of time as exposure to other student's ideas and as reflection for deciding what to include in their revised model. 


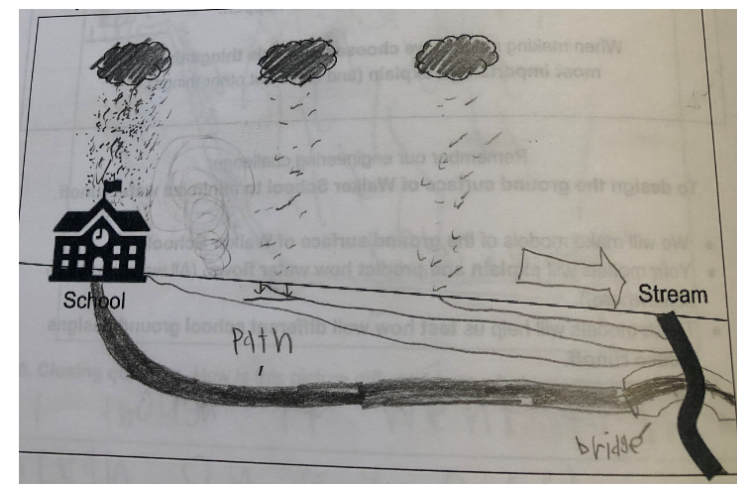

(a) Before activity

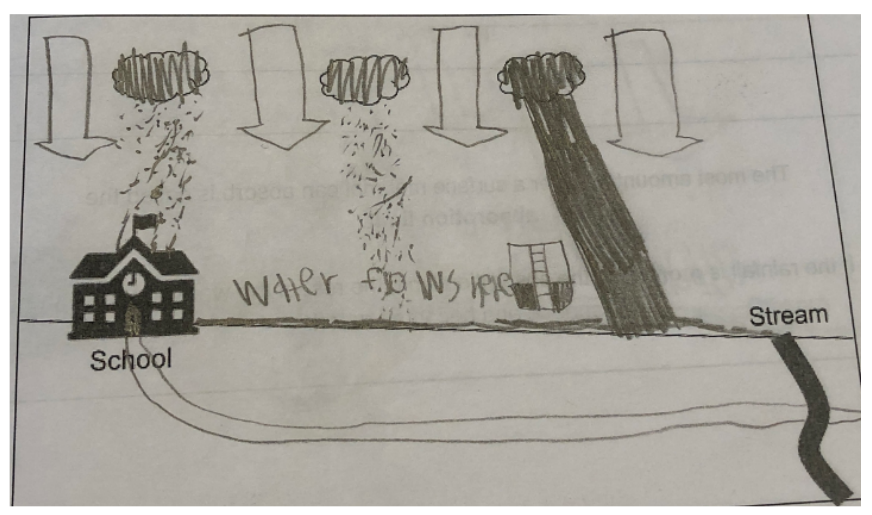

(b) After activity

Figure 8: Conceptual models of Student 8

For example, Student 8 scored a 0 in numerical quality and a 4 in pictorial quality for the conceptual model before the activity and scored a 1 in numerical quality and a 2 in pictorial quality for the conceptual model after the activity (Figure 8). Student 8 share they noticed rain gauges on other students' models during the activity that may have helped to increase the numerical quality score in the second model:

Student 8: Like, I saw how other people made it and how they drew rain gauges.

Yet, Student 8 expressed that during the activity, they spent more time with one student, and not a lot of time with the other students. The rotation of the activity seems to be an important part of learning from other students, but also the duration of time with each student:

Student 8: "We didn't really have a lot to talk about because a lot of them were a little [inaudible], there was not a lot of time and one time it was a long time, so we didn't know what to do after we talked about it.

Student 8 represented absorption in the first model but did not represent absorption in the second model. The absence of pictorial representation of absorption decreased the pictorial quality in the second model. It also should be noted that Student 8 also increased in numerical quality by noticing rain gauges from other students, as previously discussed.

\subsection{Discussion}

\section{$\underline{5.1 \text { Changes in Quality for Conceptual models }}$}

Results indicate that peer comparison can increase conceptual model quality in certain circumstances. All students interviewed who increased their model quality expressed engagement with the activity. Further, students with increased quality scores shared they engaged in socio-material processes of sharing and listening to other students, suggesting the importance of not only seeing another conceptual model, but sharing and engaging with another 
student. Even more, both peer comparison and teacher instruction are important to improve the numerical quality of a conceptual model.

Conversely, students who decreased in model quality often decreased because of the absence of a process in pictorial or numerical representations. While it is unclear what factors contributed to such decreases in model quality, a student interviewed expressed both low engagement and uneven durations of peer comparison (e.g., long durations with one student, and short durations with two other students). Yet, interviews with other students who decreased in model quality also expressed high engagement with the activity. This contradiction leaves room to question whether students knew which processes were important to represent in the activity.

Peer comparison also contributed to a diverse set of additional representations that did not represent the relevant processes, and thus did not contribute to changes in model quality. Students who revised their model with representations that did not change their model quality added representations such as parking lots, sediment, and words. In interviews, students in this category often expressed high engagement with the activity. It is plausible students learned through the activity, but learning occurred about the design context that supported students in understanding the engineering design problem. In focusing on contextually-relevant detail, students might have missed an opportunity to consider the scientific processes represented in the conceptual model. Students may have not known what is relevant or not relevant to conceptual models, which points to the need for more explicit guidance on modeling practices to help students understand what is important to represent in conceptual models within engineering design contexts.

\section{$\underline{5.2}$ Peer comparison as a learning activity}

Consistent with situated engineering learning, engagement and participation in activity is a key role in student learning [44]. Increases in model quality were best attributed to engagement in peer comparison activity. No change to model quality, but exploration of contextually-relevant representations were also attributed to engagement in the peer comparison activity. Lack of engagement and variable durations in peer comparison seemed to result in decreased model quality.

While time is important for participation in the activity, time is critically important for reflective decision-making [45]. Consistent with prior findings on reflective decision-making, such activities can both support and hinder student learning. While peer comparison as an activity seems to be effective for supporting learning when time is afforded, we highlight the need for adequate time in participation and reflection. Students with low engagement expressed that time spent in one pair was longer in duration than the other two pairs. High variability in peer comparison activities and insufficient time for reflective decision-making when revising the second model may be contributing factors to a decrease in model quality. As such, instructors and designers of curriculum units may increase student learning by sufficient time for activities and reflective decision-making.

\subsection{Limitations}


The research presented in this study is limited to a specific context with two classes at one school that both engaged in the peer comparison activity. Findings could be strengthened by having a business-as-usual group or a different treatment group without the peer comparison to be able to articulate relationships among peer comparison with the quality of students' conceptual models. In addition, students may have tired from drawing two separate conceptual models from blank boxes, which may have influenced the quality of students' models after peer critique. Future studies could use different technologies or strategies to combat the fatigue of re-representing their conceptual models from scratch, such as technology-enhanced conceptual modeling tools, to explore with more precision how and why students change their conceptual models with peer comparison activities.

\subsection{Conclusion}

This study explored the changes to students' conceptual models before and after a peer comparison activity within the context of an engineering lesson. Results suggest that peer comparisons can help to improve the quality of conceptual modeling during an engineering design curriculum. These findings have direct implications for engineering design curriculum within K-12 contexts where curriculums can design peer-to-peer learning through activities such as peer comparison.

\section{Acknowledgements}

The authors are thankful for input from many colleagues. This material is based upon work supported by the National Science Foundation under Grant No. XXXXX. Any opinions, findings, and conclusions or recommendations expressed in this material are those of the authors and do not necessarily reflect the views of the National Science Foundation.

\section{References}

[1] C. Bloebaum, P. Collopy, and G. Hazelrigg, "NSF/NASA Workshop on the Design of Large-Scale Complex Engineered Systems - From Research to Product Realization," Aerospace Research Central, Sep. 2012, doi: 10.2514/6.2012-5572.

[2] T. J. Moore, R. L. Miller, R. A. Lesh, M. S. Stohlmann, and Y. R. Kim, "Modeling in Engineering: The Role of Representational Fluency in Students' Conceptual Understanding," Journal of Engineering Education, vol. 102, no. 1, pp. 141-178, 2013, doi: 10.1002/jee.20004.

[3] M. Hu, T. Shealy, J. Grohs, and R. Panneton, "Empirical evidence that concept mapping reduces neurocognitive effort during concept generation for sustainability," Journal of Cleaner Production, vol. 238, p. 117815, Nov. 2019, doi: 10.1016/j.jclepro.2019.117815.

[4] R. Lavi and Y. J. Dori, "Systems thinking of pre- and in-service science and engineering teachers," International Journal of Science Education, vol. 41, no. 2, pp. 248-279, Jan. 2019, doi: 10.1080/09500693.2018.1548788.

[5] C. V. Schwarz et al., "Developing a learning progression for scientific modeling: Making scientific modeling accessible and meaningful for learners," Journal of Research in Science Teaching, vol. 46, no. 6, pp. 632-654, 2009, doi: 10.1002/tea.20311. 
[6] L. Markauskaite and P. Goodyear, "Epistemic Tools and Artefacts in Epistemic Practices and Systems," in Epistemic Fluency and Professional Education: Innovation,

Knowledgeable Action and Actionable Knowledge, L. Markauskaite and P. Goodyear, Eds. Dordrecht: Springer Netherlands, 2017, pp. 233-264.

[7] M. K. Watson, J. Pelkey, C. R. Noyes, and M. O. Rodgers, "Assessing Conceptual Knowledge Using Three Concept Map Scoring Methods," Journal of Engineering Education, vol. 105, no. 1, pp. 118-146, 2016, doi: 10.1002/jee.20111.

[8] F. Bornasal, S. Brown, N. Perova-Mello, and K. Beddoes, "Conceptual Growth in Engineering Practice," Journal of Engineering Education, vol. 107, no. 2, pp. 318-348, 2018, doi: https://doi.org/10.1002/jee.20196.

[9] C. L. Dym, A. M. Agogino, O. Eris, D. D. Frey, and L. J. Leifer, "Engineering design thinking, teaching, and learning," J. Eng. Educ., vol. 94, no. 1, pp. 103-120, Jan. 2005, doi: 10.1002/j.2168-9830.2005.tb00832.x.

[10] N. Guarino, G. Guizzardi, and J. Mylopoulos, "On the Philosophical Foundations of Conceptual Models," in Information Modelling and Knowledge Bases XXXI, Netherlands: IOS Press, 2020, p. 14.

[11] F. Ostuzzi and M. Hoveskog, "Education for flourishing: an illustration of boundary object use, peer feedback and distance learning," International Journal of Sustainability in Higher Education, vol. 21, no. 4, pp. 757-777, Jan. 2020, doi: 10.1108/IJSHE-09-2019-0271.

[12] W.-M. Roth, "Toward an Anthropology of Graphing," in Toward an Anthropology of Graphing: Semiotic and Activity-Theoretic Perspectives, W.-M. Roth, Ed. Dordrecht: Springer Netherlands, 2003, pp. 1-21.

[13] W. M. McCracken and W. C. Newstetter, "Text to diagram to symbol: representational transformations in problem-solving," in 31st Annual Frontiers in Education Conference. Impact on Engineering and Science Education. Conference Proceedings (Cat. No.01CH37193), Oct. 2001, vol. 2, pp. F2G-13, doi: 10.1109/FIE.2001.963721.

[14] S. L. Star and J. R. Griesemer, "Institutional Ecology, 'Translations' and Boundary Objects: Amateurs and Professionals in Berkeley's Museum of Vertebrate Zoology, 1907-39," Social Studies of Science, vol. 19, no. 3, pp. 387-420, 1989.

[15] G. J. Kelly and C. M. Cunningham, "Epistemic tools in engineering design for K-12 education," Science Education, vol. 103, no. 4, pp. 1080-1111, 2019, doi: https://doi.org/10.1002/sce.21513.

[16] P. Pande and S. Chandrasekharan, "Representational competence: towards a distributed and embodied cognition account," Studies in Science Education, vol. 53, no. 1, pp. 1-43, Jan. 2017, doi: 10.1080/03057267.2017.1248627.

[17] A. J. Cañas and P. Reiska, "WHAT ARE MY STUDENTS LEARNING WHEN THEY CONCEPT MAP?," Proceedings of the Eighth Int. Conference on Concept Mapping, p. 12, 2018.

[18] K. Moore, C. Jones, and R. S. Frazier, "Engineering Education For Generation Z," AJEE, vol. 8, no. 2, Art. no. 2, Dec. 2017, doi: 10.19030/ajee.v8i2.10067.

[19] C. T. Forbes, L. Zangori, and C. V. Schwarz, "Empirical validation of integrated learning performances for hydrologic phenomena: 3rd-grade students' model-driven explanationconstruction," Journal of Research in Science Teaching, vol. 52, no. 7, pp. 895-921, 2015, doi: 10.1002/tea.21226. 
[20] C. E. Hmelo-Silver and M. G. Pfeffer, "Comparing expert and novice understanding of a complex system from the perspective of structures, behaviors, and functions," Cognitive Science, vol. 28, no. 1, pp. 127-138, 2004, doi: 10.1207/s15516709cog2801_7.

[21] R. A. Streveler, T. A. Litzinger, R. L. Miller, and P. S. Steif, "Learning Conceptual Knowledge in the Engineering Sciences: Overview and Future Research Directions," Journal of Engineering Education, vol. 97, no. 3, pp. 279-294, 2008, doi: https://doi.org/10.1002/j.2168-9830.2008.tb00979.x.

[22] D. King and L. D. English, "Engineering design in the primary school: applying stem concepts to build an optical instrument," International Journal of Science Education, vol. 38, no. 18, pp. 2762-2794, Dec. 2016, doi: 10.1080/09500693.2016.1262567.

[23] J. Aurigemma, S. Chandrasekharan, N. J. Nersessian, and W. Newstetter, "Turning Experiments into Objects: The Cognitive Processes Involved in the Design of a Lab-on-aChip Device," Journal of Engineering Education, vol. 102, no. 1, pp. 117-140, 2013, doi: https://doi.org/10.1002/jee.20003.

[24] L. S. Vygotsky, Mind in Society: The Development of Higher Psychological Processes. Harvard University Press, 1978.

[25] J. Piaget, The Psychology Of The Child. Basic Books, 1969.

[26] P. Dourish, Where the Action Is: The Foundations of Embodied Interaction. MIT Press, 2004.

[27] W. J. Clancey, Situated Cognition: On Human Knowledge and Computer Representations. Cambridge University Press, 1997.

[28] J. Lave and E. Wenger, Situated Learning: Legitimate Peripheral Participation. Cambridge University Press, 1991.

[29] K. Dorst, “Design research: a revolution-waiting-to-happen,” Design Studies, vol. 29, no. 1, pp. 4-11, Jan. 2008, doi: 10.1016/j.destud.2007.12.001.

[30] D. A. Schön, "Designing as reflective conversation with the materials of a design situation," Knowledge-Based Systems, vol. 5, no. 1, pp. 3-14, Mar. 1992, doi: 10.1016/0950-7051(92)90020-G.

[31] A. Dominguez, H. Alarcón, and F. J. García-Peñalvo, “Active learning experiences in Engineering Education,” Jan. 2019, Accessed: Feb. 28, 2021. [Online]. Available: https://repositorio.grial.eu/handle/grial/1488.

[32] E. Jobidon et al., "Building Engineering Professional and Teamwork Skills: A Workshop on Giving and Receiving Feedback," in 2018 ASEE Annual Conference \& Exposition Proceedings, Salt Lake City, Utah, Jun. 2018, p. 30163, doi: 10.18260/1-2--30163.

[33] R. K. Sawyer and J. G. Greeno, "Situativity and Learning," in The Cambridge Handbook of Situated Cognition, M. Aydede and P. Robbins, Eds. Cambridge: Cambridge University Press, 2009, pp. 347-367.

[34] J. G. Greeno and C. van de Sande, "Perspectival Understanding of Conceptions and Conceptual Growth in Interaction," Educational Psychologist, vol. 42, no. 1, pp. 9-23, Jan. 2007, doi: 10.1080/00461520709336915.

[35] A. Carberry, S. Brunhaver, K. R. Csavina, and A. McKenna, "Comparison of written versus verbal peer feedback for design projects," International Journal of Engineering Education, vol. 32, no. 3, pp. 1458-1471, 2016.

[36] A. Schut, M. van Mechelen, R. M. Klapwijk, M. Gielen, and M. J. de Vries, "Towards constructive design feedback dialogues: guiding peer and client feedback to stimulate 
children's creative thinking," Int J Technol Des Educ, Jul. 2020, doi: 10.1007/s10798-02009612-y.

[37] M. Menekse, S. Purzer, and D. Heo, "An investigation of verbal episodes that relate to individual and team performance in engineering student teams," IJ STEM Ed, vol. 6, no. 1, p. 7, Feb. 2019, doi: 10.1186/s40594-019-0160-9.

[38] F. Rahman, C. Andrews, K. B. Wendell, N. Batrouny, and T. Dalvi, "Elementary Students Navigating the Demands of Giving Engineering Design Peer Feedback (Fundamental)," in 2019 ASEE Annual Conference \& Exposition Proceedings, Tampa, Florida, Jun. 2019, p. 32699, doi: 10.18260/1-2--32699.

[39] J. McFadden and G. Roehrig, "Engineering design in the elementary science classroom: supporting student discourse during an engineering design challenge," Int J Technol Des Educ, vol. 29, no. 2, pp. 231-262, Mar. 2019, doi: 10.1007/s10798-018-9444-5.

[40] L. D. English and D. King, "STEM Integration in Sixth Grade: Desligning and Constructing Paper Bridges," Int J of Sci and Math Educ, vol. 17, no. 5, pp. 863-884, Jun. 2019, doi: 10.1007/s10763-018-9912-0.

[41] L. Zangori, C. T. Forbes, and C. V. Schwarz, "Exploring the Effect of Embedded Scaffolding Within Curricular Tasks on Third-Grade Students' Model-Based Explanations about Hydrologic Cycling," Science \& Education, vol. 24, no. 7-8, pp. 957-981, Oct. 2015, doi: 10.1007/s11191-015-9771-9.

[42] N. Zhang, G. Biswas, K. W. McElhaney, S. Basu, E. McBride, and J. L. Chiu, "Studying the Interactions Between Science, Engineering, and Computational Thinking in a Learningby-Modeling Environment," in Artificial Intelligence in Education, Cham, 2020, pp. 598609, doi: 10.1007/978-3-030-52237-7_48.

[43] Y. S. Lincoln and E. G. Guba, Naturalistic Inquiry. SAGE Publications, 1985.

[44] A. Johri and B. M. Olds, "Situated Engineering Learning: Bridging Engineering Education Research and the Learning Sciences," Journal of Engineering Education, vol. 100, no. 1, pp. 151-185, 2011, doi: https://doi.org/10.1002/j.2168-9830.2011.tb00007.x.

[45] K. B. Wendell, C. G. Wright, and P. Paugh, "Reflective Decision-Making in Elementary Students' Engineering Design," Journal of Engineering Education, vol. 106, no. 3, pp. 356-397, 2017, doi: https://doi.org/10.1002/jee.20173. 